\title{
LOS MOVIMIENTOS JUVENILES EN LA FRANCIA DE ENTREGUERRAS
}

\author{
ARNAUd BAUBÉROT \\ Universidad París-XII (Francia)
}

RESUMEN: Más que una simple «etapa de la vida», la juventud constituía, en la Francia de entreguerras, una etapa de la existencia individual a la que se asociaban deberes y privilegios particulares. Este artículo pretende, en primer lugar, identificar las particularidades de esta etapa así como los ritos que marcan la entrada y la salida de ésta en los diferentes medios sociales. Se interesa, a continuación, por las formas de organización colectiva de los jóvenes y, más particularmente, por la aparición y el desarrollo de un nuevo tipo de agrupamiento: los movimientos de la juventud. Después de mostrar las características comunes al conjunto de estos movimientos, con especial referencia a los de inspiración religiosa y a los educativos, este estudio busca determinar en qué medida los movimientos de juventud perpetuaron, bajo una forma nueva, las organizaciones de la juventud del Antiguo Régimen, asumiendo en parte sus funciones tradicionales: la movilización de las energías juveniles en defensa del honor y de los valores de la comunidad, así como la progresiva integración de los jóvenes en el mundo de los adultos.

Palabras Clave: Movimientos juveniles. Scouts. Historia de la educación. Francia. Siglo XX.

ABSTRACT: In interwar France, youth constituted an individual stage of life associated with particular duties and privileges more than a simple age range. Therefore, the first aim of this article is to identify the specifics of this stage as well as the rites that marked its beginning and end in different social backgrounds. It will continue by inquiring about the forms of collective organization of the young and, more particularly, the rise and development of a new kind of grouping, the youth movement. After showing the common features of these movements, especially those religious and educationally based, this study will attenpt to determine to what extent youth movements perpetuated, in a new way, the Ancien Regime's youth organisations, by partly accepting its traditional roles such as the mobilization of young people's energies on behalf of honour and community values, as well as the progressive integration of the young into the adult world.

KEY WORDS: Youth movements. Scouts. History of Education. Twentieth-century France. 


\section{INTRODUCCIÓN: DEL ANTIGUO RÉGIMEN A LA MODERNIDAD}

El siglo XX no ha inventado la juventud, aunque en su transcurso haya visto afirmarse sus formas modernas de organización, y progresivamente las haya transformado en objetivo de las políticas públicas. En la sociedad francesa del Antiguo Régimen constituía ya un grupo claramente identificado, al que se accedía a través de diferentes ritos ${ }^{1}$, cuando los signos externos de la pubertad atestiguaban el fin de la infancia, y se abandonaba generalmente entre los $20 \mathrm{y}$ los 30 años, por medio del matrimonio y el ingreso en la vida adulta. La comunidad de habitantes de una misma población o de un mismo barrio asignaba a esta juventud funciones bien precisas: agrupada en «compañías», bajo la autoridad del «magistrado», «capitán» o «abad de la juventud», aseguraba el mantenimiento de las tradiciones y los valores colectivos ${ }^{2}$. Tomaba a su cargo la organización de las fiestas, desfiles y juegos ${ }^{3}$, defendía la reputación colectiva de valor y de fuerza en sus enfrentamientos con los jóvenes de las poblaciones vecinas y, con sus violencias y sus exacciones, sancionaba la transgresión de las normas ${ }^{4}$. Festivo y alborotador, en ocasiones violento, el comportamiento de los jóvenes trataba sin embargo de reproducir el de la generación anterior a su misma edad, e inscribirse de este modo en un orden natural cíclico e inmutable. Sin embargo, a lo largo del siglo XIX, la cultura tradicional, en cuyo seno se ponían a prueba la identidad y los roles de la juventud, se fue diluyendo progresivamente bajo el efecto de los progresos de la modernidad. Mientras que el éxodo rural echaba regularmente a cohortes de jóvenes, la circulación creciente de hombres y de información alentaba un movimiento profundo de desenraizamiento y de aculturación en el campos. Desde finales de siglo, los jóvenes campesinos, relativamente poco numerosos e influidos por el modelo de los tipos de vida urbanos, abandonaron sus formas tradicionales de organización. De este modo, aunque las compañías de juventud hayan podido subsistir ocasionalmente hasta la Primera, e incluso la Segunda Guerra Mundial' ${ }^{6}$, en

1 VAN GENNEP, Arnold: Le Folklore français, tomo 1, París, 1998 [1ª edición:1943], pp. 185-187.

2 Ibidem: pp. 189-197. Sobre los problemas que plantea el análisis de estas organizaciones de juventud y su evolución, ver sobre todo AGulHon, Maurice: Pénitents et francs-maçons de l'ancienne Provence, París, 1984 [1968], pp. 43-64; MuCHEMBLED, Robert: Culture populaire et culture des élites, París, 1978, pp. 205-208; et Pellegrin, Nicole: Les Bachelleries. Organisations et fêtes de la jeunesse dans le Centre-Ouest, XV'-XVIII siècle, Poitiers, 1982.

3 Conviene recordar, para calibrar la importancia de este papel, que las fiestas ocupaban alrededor de uno de cada cuatro días a finales del Antiguo Régimen.

4 VAN GENNEP, Arnold: Le Folklore français, op. cit., pp. 188-189. El charivari, por ejemplo, era realizado para castigar el matrimonio de una chica con un viejo o un forastero, o bien contra la debilidad de un marido dominado por su esposa.

5 WeBER, Eugen: La Fin des terroirs, París, 1983.

6 Existían todavía «abbayes de la jeunesse» en 1914, en las tierras de Grasse, y en 1940 en Rousset, en la comarca de Aix-en-Provence (RoBIN, Lucienne: Chambrettes des Provençaux, París, 1970). 
la mayor parte del país cayeron progresivamente en desuso. El declive del folklore campesino, y en particular de su tradición festiva, y la intervención creciente del Estado y de sus instrumentos policiales y judiciales en el ejercicio del control social, contribuyeron también a arrebatar a la juventud sus funciones tradicionales. Significativamente, la misma violencia se fue retirando del campo. Tras la Gran Guerra, la farsa y la broma se impusieron sobre la violencia ritual y la sanción de los desviados en los alborotos de la juventud rural. En la ciudad moderna, donde desembocaba el flujo continuo del éxodo rural, la juventud no recuperó ni su identidad, ni sus formas de organización, ni su papel tradicional.

Sin embargo, no desapareció del panorama social y cultural. Durante el periodo de entreguerras que analizamos, la juventud representa mucho más que una simple edad de la vida. Constituye una etapa claramente identificada en el desarrollo del individuo y se admite que, en cierta medida, puede alejarse de las normas y valores dominantes, manifestar su particularidad a través del alboroto o de una cierta exuberancia, y gozar del margen de libertad que le es característico. Limitada por la infancia y la edad adulta, la juventud incluso vio reforzar las fronteras que marcan su existencia.

En los medios populares, el fin de la escuela obligatoria, fijada en 13 años por una ley de 1882, marcaba el abandono simbólico de la infancia ${ }^{7}$, reforzado generalmente por el rito de la comunión solemne, que sancionaba el fin de la catequesis y trataba de armar moral y espiritualmente a los jóvenes en el momento de su entrada en la adolescencia, superando en importancia al rito de la primera comunión ${ }^{8}$. En el otro extremo, el servicio militar universal y obligatorio, instaurado en su forma moderna por una ley de 1905, hacía preceder al matrimonio de un periodo de uno o dos años durante los cuales la educación viril culminaba en el seno del cuartel, acentuando de este modo la ruptura que implicaba el paso a la edad adulta9. Para las jóvenes, el rito del día de Santa

7 En algunas regiones, el fin de la escolaridad queda marcado por una fiesta en cuyo transcurso se queman libros y cuadernos (PROST, Antoine: Histoire de l'enseignement et de l'éducation, tomo IV: L'école et la famille dans une société en mutation (depuis 1930), París, 2004 [1981], pp. 516-517).

8 Como consecuencia de la invitación del papa a comulgar frecuentemente (1905) y a admitir a los niños a la eucaristía desde que tienen uso de razón (1910), se operó una distinción entre la primera comunión o «comunión privada», a la edad de 7 años, y la comunión «solemne» efectuada a los 12 años. La confirmación protestante tiene lugar en torno a los 15 años de edad, y la bar-mitsva judía hacia los 13 años.

9 La Ley de agosto de 1913 fijaba la duración del servicio militar en tres años, pero las quintas de 1919 y 1920 fueron liberadas anticipadamente al cabo de dos años. La conscripción fue reducida a 18 meses en 1923, y después a un año en 1928. En 1935, ante el deterioro del contexto internacional, la duración del servicio activo fue ampliada a dos años. Por otra parte, Sabina Loriga recuerda que una de las consecuencias de la conscripción fue transformar progresivamente el Ejército en un medio relativamente homogéneo, compuesto esencialmente de jóvenes entre 20 y 25 años (LORIGA, Sabina: «L'Épreuve militaire», en LEVI, Giovanni y SCHMITT, Jean-Claude (dirs.): Histoire des jeunes en Occident, tome 2: L'époque contemporaine, París, 1996, p. 43, - ed. en castellano: Historia de los jóvenes, Madrid, 1996). 
Catalina fijaba el límite extremo de la juventud en 25 años ${ }^{10}$. Entre esos dos puntos de referencia, era perfectamente admisible que los «camaradas» de la misma edad lo pasasen bien y se divirtieran. De este modo, los bailes, a los que se asistía en bandas separadas de chicos y chicas, y donde se anudaban las primeras relaciones, aparecían como los lugares privilegiados de sociabilidad adecuados para los jóvenes de las clases populares ${ }^{11}$.

Por el contrario, en el mundo de la burguesía, estas fronteras aparecían menos marcadas. Para el joven, los estudios se prolongaban mucho más allá de la enseñanza primaria, y el servicio militar, efectuado generalmente como suboficial, permitía recuperar cada noche la indumentaria civil y el camino del hogar ${ }^{12}$. Transformado en estudiante, el joven burgués podía, no obstante, saborear los placeres de una independencia real sin tener que preocuparse de su situación material, y, a condición de salvar las apariencias, iniciarse en la sexualidad mediante aventuras más o menos breves o frecuentando prostitutas. La joven de buena familia, por el contrario, permanecía, a inicios del siglo XX, estrechamente vigilada y mantenida en una pueril inocencia que la conservaba hasta el matrimonio en un estado próximo a la infancia ${ }^{13}$. De todos modos, algunos autores ya se dedicaban en la época a denunciar este «doble rasero» de la moral burguesa, y los más avanzados abogaban por la educación sexual de las chicas $^{14}$.

Por otro lado, mientras que los efectos de la urbanización y de la modernidad contribuían a la desaparición de las agrupaciones juveniles tradicionales, aparecieron nuevas formas de organización que habían comenzado a difundirse en la segunda mitad del siglo XIX. Las primeras obras de juventud surgieron en los medios católicos y protestantes, gracias a la iniciativa de sacerdotes y de pastores, o incluso a veces de los mismos jóvenes, con un designio de revitalización y propagación de la fe ${ }^{15}$. Tras una fase de relativa desconfianza, estas obras suscitaron a partir de los años 80 del siglo XIX un fuerte interés por parte de las Iglesias ${ }^{16}$. Los apoyos eclesiásticos que recibieron entonces favorecieron su difusión, y se pudo asistir a la constitución de amplias federaciones que, como las Unions chrétiennes de jeunes gens (UCJG) — rama francesa de la YMCA (Young

10 VAn GeneP, Arnold: Le Folklore français, op. cit., p. 185.

11 Prost, Antoine: «Jeunesse et société dans la France de l'entre-deux-guerres», en Vingtième siècle (París), nº 13 (ene.-mar. 1987), p. 37.

12 Ibidem: pp. 39-40.

13 Goblot, Edmond: La Barrière et le niveau. Étude sociologique sur la bourgeoisie française moderne, París, 1930 [1925], pp. 55-57.

14 STEWART, Mary Lynn: "Science is Always Chaste": Sex Education and Sexual Initiation in France, 1880-1930 », en Journal of Contemporary History (Londres), vol. 32, n. 3 (1997), pp. 383-394.

15 Sobre la génesis de estas obras, ver CHOLVY, Gérard: Histoire des organisations et mouvements chrétiens de jeunesse en France, XIX $-X X^{e}$ siècle, París, 1999.

16 Ibidem y ChOlvy, Gérard: Mouvements de jeunesse, chrétiens et juifs. Sociabilité juvénile dans un cadre européen, 1799-1968, París, 1985, p. 49. 
Men's Christian Association)_ en el campo protestante, o la Association catholique de la jeunesse française (ACJF) alcanzaron muy pronto rango nacional. Su ejemplo incitó a la creación de agrupaciones análogas orientadas hacia diferentes formas de militantismo, sobre todo político.

\section{LOS MOVimientos de JUVENTUd TRAS LA PRIMERA GUERRA MUNDiAL}

El desarrollo de asociaciones de juventud se confirmó tras la Gran Guerra, al tiempo que se modificaban sus modos de organización y de funcionamiento. Se fue afirmando un nuevo modelo de agrupación juvenil, a la vez más centralizado a escala nacional y con voluntad de conceder mayor autonomía a los jóvenes a escala local: el movimiento de juventud. No se puede reducir la juventud a estos movimientos, ya que, organizados sobre la base de un voluntariado explícito, sólo agruparon a una minoría de jóvenes y nunca alcanzaron el grado de integración en la vida local de las agrupaciones juveniles de la Francia del Antiguo Régimen. Sin embargo, es preciso constatar que, con las debidas excepciones, se puede abordar el estudio de la juventud del periodo de entreguerras a través de sus organizaciones ${ }^{17}$. Además de la cantidad de fuentes que produce habitualmente el militantismo asociativo y que permite a los historiadores disponer de un material abundante y variado, muchos factores pueden explicar este marcado interés por los movimientos juveniles educativos. Antes que nada hay que subrayar la importancia del papel que jugaron en la integración y la socialización de la juventud, completando, a través de la transmisión de una cultura específica propia de las instituciones religiosas en el contexto en que se desarrollaban, la difusión de la cultura cívica común que operaba en la escuela republicana. Como lugares de aprendizaje de la acción colectiva y de la responsabilidad, estos movimientos contribuyeron, por otra parte, a la renovación y a la formación de los futuros cuadros laicos y eclesiásticos de estas instituciones y, por ende, de la nación ${ }^{18}$. Aún más, la excepcional amplitud que alcanzaron en los años veinte y treinta justifica el interés suscitado por los movimientos de juventud educativos, amplitud que se mide a la vez por su multiplicación, por el aumento de sus efectivos — particularmente rápido en la se-

17 Hasta donde alcanzan nuestros conocimientos, sólo la obra de Maurice Crubellier (L'Enfance et la jeunesse dans la société française, 1800-1950, París, 1979) y el artículo de Antoine Prost («Jeunesse et société...», op. cit.) estudian la juventud más allá de sus movimientos. Se encuentran igualmente algunos análisis relacionados con el periodo en LEVI, Giovanni y SCHMITT, Jean-Claude (dirs.): Histoire des jeunes..., op. cit. Esta última obra propone explorar ciertos temas particulares, pero no ofrece una síntesis de la cuestión.

18 Como ejemplo, el primer gabinete del Gobierno Provisional de la República Francesa de 9 de septiembre de 1944 incluía cinco antiguos dirigentes de la ACJF (MOLETTE, Charles: "L'Association catholique de la jeunesse française comme mouvement ", en CHOLVY, Gérard (dir.): Mouvements de jeunesse..., op. cit., p. 98). 
gunda mitad de los años treinta ${ }^{19}$ - y por su capacidad de extenderse al conjunto del territorio nacional e implicar a jóvenes de ambos sexos y de cualquier extracción social.

La ACJF, duramente afectada por la guerra, reconstituyó progresivamente sus fuerzas tras el armisticio. En 1920, sólo dos tercios de los grupos de preguerra permanecían aún activos o en vías de reorganización ${ }^{20}$. Sin embargo, la asociación conservó intacta su capacidad para reunir en su seno a jóvenes procedentes de diferentes capas sociales, y se componía por esas fechas de un $50 \%$ de campesinos, un 19,5\% de empleados, un 16,5\% de obreros y un $14 \%$ de estudiantes ${ }^{21}$. En 1930, en vísperas de la profunda reorganización que conduciría al desarrollo de movimientos especializados, la ACJF agrupaba a 180.000 miembros, es decir, 40.000 más que en $1914^{22}$. El proceso de especialización que entonces se puso en marcha dio lugar a diversos movimientos, entre los cuales figuraba la Jeunesse ouvrière chrétienne (JOC), que contaba con $1.230 \mathrm{sec}-$ ciones y calculaba influir sobre 130.000 jóvenes obreros (con 45.000 adherentes) en 1939, y la Jeunesse agricole chrétienne (JAC), con 1.485 secciones y 28.000 cotizantes en 1938. Este crecimiento resulta aún más patente para el caso del escultismo católico masculino. Fundada en 1920, la asociación de los Scouts de France contaba en 1924 entre 5.000 y 6.000 adherentes, repartidos en 14 provincias. Tras diez años de existencia, sus 24 provincias metropolitanas y sus cinco provincias coloniales reunían a más de 25.000 jóvenes. En vísperas de la Segunda Guerra Mundial, esta cifra se elevaba a unos 72.000 miembros en 35 provinciales (de las cuales 9 eran provincias coloniales; otra, una "provincia extensión» para los scouts minusválidos, y la última, una «provincia» para los franceses del extranjero) ${ }^{23}$. Los movimientos católicos femeninos alcanzaron igualmente una amplitud destacada. En 1930, las secciones juveniles de la $\mathrm{Li}$ gue patriotique des Françaises contaban con 190.000 adherentes repartidos en tres ramas: Jeunes urbaines (95.000), Jeunes rurales agricoles (65.000) y Enseignement libre (30.000). En cuanto a las Fédérations diocésaines de jeunes filles, presentes en más de dos tercios de los departamentos, se puede estimar que encuadra-

19 Coutrot, Aline: «Youth Movements in France in the 1930s», en Journal of Contemporary History (Londres), vol. 5, n 1 (1970), p. 29.

20 En 1914, la ACJF contaba con alrededor de 3.000 grupos. En 1920 había 1.100 grupos activos y 800 en vías de reconstitución. Alrededor de 15.000 miembros de la asociación murieron durante la guerra (CHOLVY, Gérard: Histoire des organisations et mouvements..., op. cit., pp. 119 et 121).

21 MOLETTE, Charles: «L'Association catholique...», op. cit., p. 97. Si se comparan estas cifras con la estructura de población activa, se constata que los obreros (poco menos de un tercio de los activos) estaban subrepresentados, mientras que los estudiantes estaban ampliamente sobrerrepresentados.

22 ChOlvy, Gérard: Histoire des organisations et mouvements..., op. cit., p. 123.

23 LANEYRIE, Philippe: Les Scouts de France. L'évolution du Mouvement des origines aux années 80, París, 1985, p. 86. Sobre el crecimiento del escultismo católico femenino, nos remitimos a CHeroutre Marie-Thérèse: Le Scoutisme au féminin: les Guides de France, 1923-1998, París, 2002. 
ron a alrededor de 300.000 personas $^{24}$. En 1939, el porcentaje de chicas jóvenes afiliadas a un movimiento católico se podía evaluar en un 15\%, cifra sin equivalente en la historia contemporánea de Francia ${ }^{25}$.

Los movimientos juveniles de las religiones minoritarias conocieron igualmente un crecimiento notable en la etapa de entreguerras. En el entorno protestante, dos movimientos se afirmaron con fuerza en este periodo. La asociación de los Éclaireurs unionistes, fundada en 1911 en el seno de la UCJG, se hizo autónoma en 1920 y se implantó poco a poco en la mayoría de las parroquias protestantes. Sus efectivos pasaron de 2.000 a 10.000 adherentes entre 1918 y 1937. Las Unions chrétiennes de jeunes filles (UCJF) alcanzaron por su parte la cifra de 15.000 miembros en 1929, frente a 9.000 antes de la guerra, y se convirtieron en el movimiento juvenil protestante más importante desde el punto de vista numérico ${ }^{26}$. La situación de la rama masculina de las Unions chrétiennes parece, en cambio, más contrastada. La guerra afectó profundamente a las UCJG, y el ejemplo de la Union de Paris, que conoció por ese entonces un desarrollo espectacular, no parece que se pueda generalizar al conjunto de las UCJG francesas ${ }^{27}$. En el judaísmo, el crecimiento de los movimientos de juventud en el transcurso de los años veinte se tradujo en una multiplicación de asociaciones, generalmente constituidas sobre la base de un proyecto religioso o político particular. La corriente de renovación religiosa e identitaria impulsada por la creación de la Association des jeunes juifs en 1911, se pudo continuar a través de Chema Israël, fundada por el gran rabino Maurice Liber en 1919, y la Union universelle de la jeunesse juive, formada en 1923. En 1926, la sinagoga liberal de la calle Copernic de París lanzó la Jeunesse libérale israélite, mientras que la comunidad de Estrasburgo de estricta observancia Etz Hayim se dotó de la asociación Yechouroun para permitir a sus jóvenes la práctica del deporte y de acti-

24 Cholvy, Gérard e Hilaire, Yves-Marie (dirs.): Histoire religieuse de la France contemporaine, tome 2: 1880-1930, Toulouse, 1986, pp. 373 y 396; y Roux Jacqueline: Sous l'étendard de Jeanne. Les Fédérations diocésaines de jeunes filles, 1904-1945. Une ACJF féminine?, París, 1995.

25 Chaline, Nadine-Josette, Demier, Francis y LE BEGUEC, Gilles: "Jeunesse et mouvements de jeunesse en France aux $\mathrm{XIX}^{\mathrm{e}}$ et $\mathrm{XX}^{\mathrm{e}}$ siècles. Influences sur l'évolution de la société française», en COMMISSION INTERNATIONALE D'HISTOIRE DES MOUVEMENTS SOCIAUX ET DES STRUCTURES SOCIALES: La Jeunesse et ses mouvements, influence sur l'évolution des sociétés aux XIX et $X X^{e}$ siècles, París, 1992, p. 103.

26 En 1909, las UCJF contaban con 253 uniones de mayores y 84 uniones de menores. En 1929 englobaban 450 uniones de mayores y 200 uniones de menores (FABRE, Rémi: «Croissance et diversification des mouvements de jeunesse d'inspiration protestante au lendemain de la Première Guerre mondiale», en Bulletin de la Société de l'bistoire du protestantisme français, (París), nº 134 (1988), p. 31).

27 Ibidem. De todos modos, hay que precisar que aún no se ha dedicado ninguna monografía a la historia de la Alliance nationale des UCJG durante el periodo de entreguerras. Véase BAUBÉROT, Arnaud: "L'invention d'un scoutisme d'inspiration protestante, les Éclaireurs Unionistes et les Unions Chrétiennes de Jeunes Gens», en Bulletin de la Société de l'bistoire du protestantisme français (París), vol. 143-III, julio-septiembre 1997, pp. 371-435. 
vidades al aire libre. Este último movimiento se extendió con rapidez al conjunto de Alsacia-Lorena, y luego a París. La corriente sionista poseía igualmente sus organizaciones de juventud, entre las cuales figuraba el Betar, fundado en 1928 y muy marcado por el nacionalismo autoritario y el militarismo, y el movimiento Hachomer Hatzaïr, implantado en Francia a comienzos de los años treinta y orientado más bien hacia una forma de socialismo laico. Como único movimiento realmente ecléctico, el escultismo judío apareció en 1923. Constituido en movimiento de Éclaireurs israélites de France en 1927, buscó atraer al mayor número posible de jóvenes, piadosos o no, sionistas o no. Sin embargo, este pluralismo estuvo en el origen de numerosos debates sobre el estatuto y contenido del mínimo religioso común a los miembros de la asociación ${ }^{28}$.

Por el contrario, el ámbito del militantismo laico y anticlerical no suscitó la creación de movimientos de juventud durante el periodo de entreguerras. Incluso mantuvo al respecto una cierta desconfianza. Los Éclaireurs de France y la sección neutra de la Fédération française des éclaireuses ${ }^{29}$, únicos movimientos de juventud que no hacían alusión a un origen o a una adscripción confesionales, desarrollaron un concepto de neutralidad religiosa muy alejado de la laicidad militante y contaron entre sus fundadores y sus cuadros dirigentes con católicos y protestantes que eran practicantes notorios. Muy probablemente, la ausencia de apoyo por parte de los medios laicos explica su modesto desarrollo ${ }^{30}$. Por el contrario, la potente y muy laica Ligue de l'enseignement poseía su propia red de obras extraescolares y post-escolares (sobre todo colonias de vacaciones y círculos recreativos) cuyo estilo y métodos diferían claramente de los que adoptaban los movimientos confesionales ${ }^{31}$.

Más allá de sus diferencias en función de la inspiración religiosa y la zona de implantación, y más allá de las especificidades pedagógicas de cada uno, los movimientos de juventud educativos compartían un cierto número de rasgos comunes que les distinguían de las organizaciones de preguerra, y permiten interpretar su crecimiento en los años veinte y treinta como la afirmación de un modelo particular de sociabilidad juvenil ${ }^{32}$.

28 Delmaire, Danielle: «Les Mouvements de jeunesse juifs en France, 1919-1939 » y MiCHEL, Alain: «Les Éclaireurs israélites de France, 1923-1939», en CHOLvy, Gérard (dir.): Mouvements de jeunesse..., op. cit., pp. 313-348.

29 La Fédération française des éclaireuses, fundada en 1921, reunía una sección unionista (protestante) y una sección neutra. En 1927 se incorporó una sección israelita.

30 Los Éclaireurs de France contaban solamente con 15.000 mienbros en 1939 (FABRE, Rémi: «Les Mouvements de jeunesse dans la France de l'entre-deux-guerres», en Le Mouvement social (París), n 168 (julio-septiembre de 1994), p. 11.

31 COUtrot, Aline: «Le Mouvement de jeunesse, un phénomène au singulier», en CHOLVY, Gérard (dir.): Mouvements de jeunesse..., op. cit., p. 113. Sobre las diferencias de objetivo y método que separaban las obras laicas y las obras católicas, ver especialmente: DESSERTINE, Dominique y MARADAN, Bernard: L'Âge d'or des patronages (1919-1939). La socialisation de l'enfance par les loisirs, Vaucresson, 2001.

32 Seguimos aquí, aunque sólo parcialmente, la reflexión propuesta por Aline Coutrot en su artículo «Le Mouvement de jeunesse...», op. cit., pp. 109-123. 
La primera y más visible de estas particularidades reside en la necesidad que manifestaban, tanto los movimientos como sus miembros, de afirmar su identidad común recurriendo a un cierto número de símbolos y manifestaciones. Uniformes, estandartes, saludos y desfiles no eran la herencia exclusiva del escultismo o de las organizaciones de extrema derecha, sino que afectaban al conjunto de las agrupaciones juveniles ${ }^{33}$. Cada asociación — cada sección local a veces - poseía una bandera y un himno que invitaban a la reunión y a la expresión del orgullo colectivo. Se repartía una insignia que los adheridos llevaban habitualmente en el ojal o sobre su traje durante las reuniones. La vida del grupo estaba jalonada de ceremonias, y un ritual más o menos preciso marcaba generalmente las etapas de la progresión de los jóvenes en el movimiento. En un registro similar, los códigos, las leyes y los juramentos se dirigían tanto a la conformación de su militancia como al refuerzo de su sentimiento de pertenencia al grupo. Divisas y consignas movilizaban y orientaban las energías. A las fórmulas de equilibrio de las asociaciones de fines del XIX — «Piedad, estudio, acción» para la ACJF, "Cuerpo, alma, espíritu" para las UCJG- sucedió el tono imperativo y fogoso de los movimientos más recientes, como el «iSiempre listos!» de los scouts y exploradores de todas las confesiones, o el «Ver, juzgar, actuar» de los movimientos de Acción Católica.

En el exterior de los movimientos, los símbolos, ritos y consignas que estructuraban su funcionamiento fueron percibidos como los factores determinantes de su dinamismo, y suscitaron diversas imitaciones. Se puede citar el ejemplo de los Cours vaillants, lanzados en 1929 a partir del semanario homónimo. En esa época la Union catholique des æuvres de France (UOCF), enfrentada a un relativo declive de los círculos recreativos infantiles que sufrían la competencia del escultismo, se enfrentó a las fuertes reticencias que suscitaba en su seno el proyecto de crear una unión de círculos juveniles centralizada. El lanzamiento de la revista Cours vaillants respondió a una tentativa de revitalizar los círculos recreativos constituyendo una especie de comunidad informal de niños que adoptó algunos rasgos característicos de los movimientos juveniles sin por ello recoger su modo de organización. En 1933, el semanario propuso a sus 42.000 suscriptores adoptar una insignia común. Al año siguiente se planteó el uso de un uniforme, y algunos círculos recreativos se organizaron en equipos sobre el modelo de las patrullas scouts. En 1935, los Coeurs vaillants se dotaron de un sistema de grados y de un ceremonial de entrega de insignias. En abril de 1935, el 51 ${ }^{\circ}$ Congreso de la UOCF decidió finalmente crear una Organisation nationale des cœeurs vaillants. Un año más tarde, el semanario tiraba 120.000 ejemplares y la fórmula se extendió a las chicas con la creación de las Âmes vaillantes en el cuadro de la Fédération des patronages féminins ${ }^{34}$.

El dinamismo de los movimientos de juventud y la fuerza movilizadora que entrañaban sus formas externas suscitaron igualmente recuperaciones o imita-

33 Ibidem, p. 117; y COUTROT, Aline: «Youth Movements...», op. cit., p. 32.

34 FEROLDI, Vincent: La Force des enfants. Des crurs vaillants à l'ACE, París, 1987. 
ciones por parte de las formaciones políticas de izquierda. De este modo, el movimiento de los Pioneros, lanzado por el Partido Comunista Francés en 1925, copiaba abiertamente del escultismo el uniforme, la promesa y la ley, al, igual que algunas actividades que adaptó a sus propios objetivos educativos y políticos $^{35}$. Si el proyecto, formulado en 1931, de crear Scouts socialistas no parece haberse plasmado nunca en la práctica ${ }^{36}$, por contra el movimiento de los Faucons rouges (halcones rojos), importado de Austria al año siguiente, logró reunir hasta 5.000 adherentes en 1936. Su modo de organización, su uniforme y algunos aspectos de su pedagogía se inspiraban igualmente en el escultismo, de donde procedían por otra parte algunos de sus cuadros ${ }^{37}$. Por su lado, las Jeunesses socialistes (JS) adoptaron una insignia - cuyo motivo, una mano sosteniendo una rama de olivo, recogía el de los Jeunes gardes belgas- cuyo uso se hizo obligatorio para los militantes desde 1928. A lo largo de los años treinta, las Juventudes Socialistas, frecuentemente movilizadas para hacer tremolar sus banderas, cantar la Internacional y declamar sus consignas y eslóganes en manifestaciones y desfiles, hubieron de vestir un uniforme completo ${ }^{38}$.

En realidad, la utilización de manifestaciones externas de adscripción con el fin de movilizar a los jóvenes no era una cosa nueva. En las décadas de preguerra, las sociedades deportivas y algunas obras ya habían recurrido a los uniformes y a las paradas en una perspectiva claramente nacionalista y revanchista. En los años diez, el naciente escultismo conservaba esa costumbre, al tiempo que la orientaba en un sentido acorde con los principios higienistas de la época: el pantalón corto, la camisa amplia con mangas remangadas y cuello ampliamente abierto y el pañuelo ligeramente anudado permitían a los miembros moverse libremente, al tiempo que la circulación del aire fresco saneaba y endurecía el cuerpo ${ }^{39}$. En este estilo, menos militarizado y más «relajado», se inspiraron la mayor parte de los

35 MerCIER, Lucien: «Enfance et Parti communiste français: le scoutisme rouge, 1921-1933», en DuClert, Vincent, FABre, Rémi y Fridenson, Patrick (dirs.): Avenirs et avant-gardes en France, XIX ${ }^{e}-X X^{e}$ siècles. Hommage à Madeleine Rebérioux, París, 1999, pp. 342-356.

36 El único estudio existente sobre la juventud socialista en este periodo es el de DeLPORTE, Christian: «Les Jeunesses socialistes dans l'entre-deux-guerres», en Le Mouvement social (París), $\mathrm{n}^{\circ}$. 157 (octubre-diciembre de 1991), pp. 33-66. Véase, p. 44.

37 Mercier, Lucien: «Pionniers et Faucons rouges. Des scoutismes rouges dans la France de l'entre-deux-guerres», en CHOLvy, Gérard: Le Scoutisme, un mouvement d'éducation au XX siècle. Dimensions internationales. Actes du colloque international de Montpellier, 21-23 septembre 2000, Montpellier, 2003, pp. 143-156.

38 DelPORTE, Christian: «Les Jeunesses socialistes...», op. cit., pp. 47 y 54-55.

39 BAubérot, Arnaud: «Scoutisme», en ANDrieu, Bernard (dir.): Dictionnaire du corps, París, 2006, pp. 460-462. Este uniforme, que algunos juzgaban demasiado «exótico» y «relajado», fue un obstáculo para la penetración del escultismo en el entorno de la burguesía francesa. De hecho, hasta la Gran Guerra, un gran número de tropas de exploradores adoptaron un estilo más estricto y militarizado que el que preconizaba Baden-Powell. Sobre la influencia de Baden-Powell se puede ver BAubérot, Arnaud: "Aux sources des scoutismes français. Les protestants et la méthode de Baden-Powell», en CHOLVY, Gérard (Ed.), Le Scoutisme..., op. cit., pp. 27-42. 
movimientos juveniles que adoptaron un uniforme durante el periodo de entreguerras. Camisa deportiva, pañuelo o corbata, o boina ocasional, lo importante no era ofrecer un aspecto marcial, sino celebrar la voluntad de actuar colectivamente y marcar la adhesión y fidelidad al movimiento y a sus valores. Incontrastablemente, los jóvenes no percibieron estos signos y manifestaciones colectivas como una coacción. Por el contrario, esta demostración de pertenencia se vivía como un elemento dispensador de orgullo y dignidad. Además, demostraciones de este tipo no conllevaban el menor rastro de ruptura o de oposición a los valores dominantes de la sociedad. Más allá del movimiento, expresaban el orgullo de ser cristiano o judío, de ser un buen ciudadano fiel al país y a la comunidad, y luego, con el desarrollo de los movimientos especializados, el orgullo de ser obrero, agricultor o marino. A ese respecto, el movimiento juvenil de entreguerras recuperó la función propia de las agrupaciones juveniles tradicionales de la Francia del Antiguo Régimen: manifestaba de forma visible la existencia de una cultura propia de la juventud, al tiempo que designaba a los jóvenes como defensores de los valores de la comunidad, y trabajaba de este modo en favor de su futura integración en el mundo adulto.

Igualmente, los movimientos juveniles se distinguieron de las obras de preguerra por la mayor autonomía y responsabilidades que concedían a los jóvenes. En efecto, se fue imponiendo progresivamente la idea según la cual la educación y la evangelización de los jóvenes debían ser realizadas por ellos mismos. Fuera el jefe de una patrulla scout, el responsable de una sección o el presidente de una asociación, los jóvenes permanecían la mayor parte del tiempo al mando de los movimientos y disponían de un margen de decisión y de acción considerables. Esta situación no resultaba totalmente inédita, ya que desde fines del siglo XIX las estructuras locales y nacionales de las UCJG y de la ACJF eran controladas por los propios jóvenes. La verdadera innovación de la época de entreguerras reside más bien en el hecho de que esta autonomía y responsabilidad se amplió a las jóvenes, gracias a movimientos femeninos como las Guides de France o la Jeunesse ouvrière chrétienne féminine (JOCF), y a los adolescentes, sobre todo por medio del escultismo. Es evidente que la Gran Guerra estuvo en parte en el origen de esta evolución. En efecto, la movilización de la mayor parte de los hombres adultos permitió una cierta forma de emancipación de las mujeres y de las adolescentes, al tiempo que la necesidad de adiestrar a la retaguardia en la lógica de la guerra total conducía a que la propaganda valorara sus iniciativas y su implicación en el esfuerzo común. No obstante, los progresos de la autonomía de las jóvenes y las adolescentes reflejaron también evoluciones más profundas. Olvidada por largo tiempo, la cuestión de la educación femenina emergió y suscitó a fines del siglo XIX la formación de obras destinadas a las jóvenes, como la UCJF en el entorno protestante ${ }^{40}$ o los grupos Noëlistes, constituidos a partir de

40 La Alliance nationale des UCJF fue fundada en 1894, pero las Uniones femeninas existían en algunas parroquias protestantes desde 1849 (Poujol Geneviève: Un Féminisme sous tutelle. Les protestantes françaises, 1810-1960, París, 2003, pp. 39-44). 
la revista Le Noël, en los medios católicos. También desde fines del siglo XIX, una amplia publicística se dedicó a perfilar las particularidades psicológicas de la adolescencia, subrayando no sólo las dificultades que planteaba esta «edad crítica», sino también todas sus potencialidades ${ }^{41}$. Esta literatura alimentó la reflexión de aquéllos que, en la estela de las teorías de la moderna educación, consideraban que era mejor tener en cuenta los impulsos y aspiraciones propias de esta edad, ya que no era suficiente reclutar a los jóvenes para transmitirles valores cívicos, morales o religiosos. Esta percepción positiva de la juventud y las concepciones pedagógicas que derivaban de ella animaron los movimientos juveniles de entreguerras. La educación activa, el aprendizaje por el descubrimiento y la experiencia fueron situados en un lugar destacado, mientras que la crítica de los métodos tradicionales de enseñanza a veces se situaba en las fronteras del antiintelectualismo. En el seno de estos movimientos también se dedicó una gran atención a la práctica de actividades al aire libre y al desarrollo de las facultades físicas del individuo. Y las funciones de dirección y de encuadramiento se realizaron desde entonces en un estilo pretendidamente menos formal. El «líder» o el «jefe» ideal —a veces explícitamente opuesto al contramodelo del maestro de escuela- era también un joven, próximo al grupo, con el que compartía experiencias, alegrías y desgracias, deseoso de hacer progresar a cada uno mediante el ejemplo y los consejos amistosos antes que por órdenes o lecciones $^{42}$. En muchos sentidos, los movimientos de juventud aparecen como vectores de difusión o ejecución de las teorías de la moderna educación, en una época donde éstas, a pesar de los incesantes esfuerzos de sus promotores, seguían encontrando dificultades para penetrar en la institución escolar.

La generalización de la práctica de la acampada aparece como uno de los signos más tangibles tanto de la autonomía conquistada por los jóvenes como de la influencia que ejercía la nueva pedagogía en el seno de los movimientos de juventud. Las primeras experiencias se desarrollaron en Francia alrededor de 1900, de forma más o menos simultánea entre los jóvenes miembros del Touring club de France y un grupo de excursionistas de las UCJG. Aparte de su dimensión deportiva y su interés turístico, el camping era apreciado por los lazos de amistad que suscitaba entre los campistas y el espíritu comunitario que surgía del grupo. Rápidamente, los promotores protestantes de acampadas también le atribuyeron un valor educativo. Desde 1906, los campos de estudiantes de segunda enseñanza encuadrados por estudiantes fueron organizados según el modelo de las realizaciones de las YMCA americana, suiza y holandesa. Como empresa pedagógica, el campamento permitiría sustituir la autoridad de los pedagogos habituales (padres, profesores y pastores) por una presencia más familiar, más atenta y, por lo tanto, capaz de permitir la expansión del entusiasmo y de las cualidades de los adolescentes, ejerciendo sobre ellos una in-

41 Thiercé, Agnès: Histoire de l'adolescence, París, 1999, pp. 217 y ss.

42 Como ejemplo se puede ver BreITTMAYER, Paul: Sois un chef! Notes et expériences sur le système des patrouilles à l'usage de leurs chefs, París, 1920 (reediciones en 1926 y 1934). 
fluencia más profunda ${ }^{43}$. El campo de Domino en la isla de Oléron, que los estudiantes protestantes organizaron anualmente a partir de 1910, jugó el papel de laboratorio en cuyo seno se elaboraron métodos y técnicas que se aplicarían, tras la Gran Guerra, al conjunto de los movimientos juveniles protestantes, y probablemente a otros. La práctica de acampadas se generalizó en las diferentes asociaciones de escultismo desde inicios de los años veinte, y después se extendió progresivamente a la mayor parte de los movimientos. A inicio de los años treinta, ya estaba admitido como legítimo y benéfico que a intervalos regulares los grupos de chicos o chicas dejasen su domicilio habitual, abandonasen su familia, su trabajo o estudios, y pasasen algunos días en la naturaleza, dedicados a sí mismos. A mitad de camino entre la «robinsonada» y la microsociedad utópica, el campamento obedecía a ritmos, ritos y normas que le eran propios y le distinguían de la vida social normal. Funcionando de un modo casi autárquico, su desarrollo, dirección, gestión de los aspectos económicos y sanitarios correspondía a los propios campistas. En fin, la profundidad e intensidad de las experiencias vividas en el campamento - durante las excursiones o exploraciones, grandes juegos, fuegos de campamento o incluso manifestaciones religiosas - daban al grupo de jóvenes una dimensión auténticamente comunitaria. El reconocimiento de una cierta autonomía como privilegio de juventud no era, por supuesto, algo nuevo, pero incontestablemente los movimientos de entreguerras lograron dar formas y dimensiones inéditas a este privilegio.

Esta autonomía era, sin embargo, estrechamente controlada. Esta es, en efecto, otra característica de los movimientos juveniles de entreguerras: el incremento de las responsabilidades y el margen de maniobra reservados a los jóvenes se acompañó de una creciente centralización de los órganos de dirección y un reforzamiento de la influencia ejercida por las instituciones eclesiásticas. A título de ejemplo, la introducción del escultismo en las Unions chrétiennes de jeunes gens en 1911 se había efectuado de forma muy descentralizada. Cada tropa dependía del comité de la Unión local que había suscitado su formación, y la Alianza Nacional de las UCJG (cuyo comité era elegido democráticamente por los delegados de las uniones locales) se mantenía recluida en un papel de promoción del método escultista y de coordinación de sus experiencias. La separación de las UCJG en octubre de 1920 dio lugar al movimiento de los Éclaireurs unionistes de France, fuertemente centralizado y jerarquizado. Los difíciles debates que condujeron a esta separación fueron percibidos por los exploradores como la expresión de un conflicto generacional, y los jóvenes jefes y cuadros del nuevo movimiento vivieron esta ruptura como un triunfo de sus aspiraciones a la autonomía y de su derecho a disponer de sí mismos. A partir de entonces, sin embargo, se encontraron integrados en una cadena de mando que del jefe de tropa al comisario nacional, pasando por los comisarios de sección, distrito y

43 BAubérot, Arnaud: «La Nature éducatrice. La pédagogie du camp dans les mouvements de jeunesse protestants», en Ethnologie française (París), vol. 31, n. 4 (octubre-diciembre de 2001), pp. 621-629. 
región, imponía el deber de obediencia a sus superiores jerárquicos. En la cúspide, la dirección del movimiento la ostentaba un comité en el que participaban representantes de las principales Iglesias y obras protestantes, y cuya presidencia quedaba confiada a un pastor ${ }^{44}$. El porcentaje cada vez más importante de tropas vinculadas a las parroquias y la implicación de numerosos pastores jóvenes en el escultismo contribuyeron por otra parte a incrementar de forma muy clara la influencia de las Iglesias protestantes sobre el movimiento de los Éclaireurs unionistes en el transcurso de los años treinta.

Por su parte, los promotores del escultismo católico se enfrentaron, desde antes de la Gran Guerra y hasta mediados de los años veinte, a la hostilidad de un cierto número de obispos y publicistas vinculados al catolicismo intransigente. Entre sus quejas figuraban sobre todo la excesiva autonomía que el escultismo parecía otorgar a sus jóvenes jefes, en detrimento del legítimo control que debía ejercer el clero sobre las obras de juventud. Buscando apoyo en la cumbre del aparato eclesiástico, los Scouts de France trataron de obtener el reconocimiento necesario para su implantación. En 1921 obtuvieron la autorización y bendición del cardenal arzobispo de París, y después, tras haber sido animados y aprobados en diferentes ocasiones por el Vaticano, recibieron su consagración definitiva en Roma, en septiembre de 1925, de manos del papa Pío XI, que les designó como «Caballeros de la Acción Católica». Entre 1920 y 1930 se precisaron los objetivos de la asociación: además de la formación de jóvenes fieles a la Patria y a la Iglesia, se trató de dar cuerpo a un orden scout, mezcla de ideal caballeresco y de espíritu de conquista, y que se veía como prefiguración del futuro orden social cristiano $^{45}$. En el mismo momento, los Scouts de France se dotaron de un aparato fuertemente centralizado, colocado sobre la doble influencia de una jerarquía de capellanes que acompañaban al movimiento en sus diferentes escalones, y de jefes militares, muy a menudo próximos al movimiento monárquico de l'Action Française, que ocupaban una buena parte de los puestos de dirección en el ámbito nacional y provincial ${ }^{46}$. Sobre el terreno, a diferencia de los centros de recreo, las tropas scouts no estaban encuadradas por miembros del clero. De todos modos, los capellanes, que disponían de las ventajas de la veteranía y de la autoridad moral que les confería su edad y estado eclesiástico, intervenían a menudo en la elección de los jefes y en la vida de las unidades.

Como último ejemplo, la Acción Católica, impulsada por Pío XI en 1930 y establecida por la Asamblea de cardenales y obispos de Francia en 1931, tuvo como consecuencia directa acentuar la tutela de la jerarquía eclesiástica sobre

44 BAUBÉROT, Arnaud: L'Invention d'un scoutisme chrétien. Les Éclaireurs unionistes de 1911 à 1921, París, 1997, pp. 171-178. Sobre las fuentes existentes para su estudio, véase BAUBÉROT, Arnaud: «Les archives des Éclaireurs Unionistes de France», en Bulletin de la Société de l'bistoire du protestantisme français (París), vol. 143-III (julio-septiembre de 1997), pp. 535-539.

45 GuÉRIN, Christian: L'Utopie des Scouts de France. Histoire d'une identité collective, catholique et sociale, 1920-1950, París, 1997, pp.155-227.

46 LANEYRIE, Philippe: Les Scouts de France..., op. cit., pp. 69-103. 
las obras y los movimientos católicos. En su Petit catéchisme d'Action catholique, aparecido en Roma en 1930, monseñor Fontenelle presentaba los dos fundamentos de la "participación de los laicos en el apostolado jerárquico». Además del tema clásico del sacerdocio que, concebido «en un sentido amplio», invitaba a todos los bautizados a participar en la Iglesia, el autor desarrollaba la más moderna teoría del «mandato» confiado por la jerarquía a los miembros laicos de las organizaciones de Acción Católica. A la lógica dominante desde inicios del siglo XX, la de la ACJF de la preguerra, dirigida por laicos exentos de mandato sin implicación de la Iglesia y en cuyo seno el capellán era un simple asistente eclesiástico, le sucedió una nueva concepción del compromiso de los laicos, ahora descritos como «auxiliares y cooperadores del clero», y un reforzamiento del control que sobre ellos ejercía la jerarquía eclesiástica ${ }^{47}$.

Un verdadero deseo de captar y reunir a jóvenes procedentes de las diferentes clases sociales animaba a estos movimientos de juventud. Más que un deseo en sí, esta ambición a veces derivaba directamente del proyecto de evangelización o de revitalización de la fe que hizo nacer a los movimientos, y traducía, más allá de un innegable paternalismo, la aspiración cristiana al universalismo que todos decían compartir. De este modo, las UCJG, fundadas a mediados del siglo XIX con el fin de reunir y organizar a los jóvenes protestantes de cualquier denominación, lograron que en su seno convivieran tanto los hijos de la gran burguesía protestante como los empleados, los obreros, y de forma más excepcional, los campesinos. Por su parte, desde su creación en 1886, la ACJF trató de convertirse en punto de encuentro entre burgueses y obreros a fin de que los primeros abandonasen su frivolidad y se pudieran dar esperanzas a los segundos. De todos modos, en vísperas de la Gran Guerra, este impulso universalista no se había plasmado en la práctica sino de forma mediocre. Del lado protestante, la aparición en 1898 de una Fédération française des associations chrétiennes d'étudiants alejó de las UCJG a una parte de la juventud burguesa. Entre los católicos, a pesar de la ambición declarada de abrir la asociación a todos los jóvenes «capaces de ejercer a su alrededor una cierta influencia», y la constitución, a partir de 1896, de círculos rurales y obreros, la ACJF siguió influyendo de forma predominante sobre las elites sociales ${ }^{48}$.

A inicio de los años veinte se planteó con más intensidad la cuestión de la apertura de los movimientos juveniles confesionales a todas las clases sociales. Durante la guerra, la mezcolanza social propiciada por la vida en el Ejército permitió a los jóvenes burgueses católicos, a los sacerdotes y a los seminaristas movilizados $^{49}$ tomar conciencia de la fuerte descristianización que afectaba a los

47 Cholvy, Gérard e Hilaire, Yves-Marie (dirs.): Histoire religieuse de la France contemporaine, tome 3: 1930-1988, Toulouse, 1988, p. 29.

48 CHOlvy, Gérard: Histoire des organisations et mouvements..., op. cit., p. 112-115.

49 Desde la Ley de 1889, los eclesiásticos eran obligados a realizar el servicio militar. Durante la Gran Guerra, más de 33.000 religiosos, sacerdotes y seminaristas fueron movilizados. La mitad de ellos fueron destinados a los servicios sanitarios y 1.500 sirvieron como capellanes. Los otros 
medios populares urbanos. La revolución rusa, la formación del Partido Comunista (PCF) en 1920 y la acentuación de los antagonismos sociales alimentaron el miedo a un «incendio revolucionario» e incitaron a la Iglesia católica a intentar franquear el foso que la separaba del mundo obrero. Los movimientos juveniles aparecieron entonces como un instrumento privilegiado para reconquistar ese mundo. Por esta razón, y porque el método de Baden-Powell se percibía entonces como un medio adecuado para transmitir tanto el sentido de la disciplina como los valores cívicos y cristianos a los jóvenes de los barrios populares, los jesuitas de Action populaire alentaron el nacimiento de los Scouts de France, y el escultismo católico mantuvo una impronta popular dominante hasta inicio de los años treinta ${ }^{50}$. En lo que concernía a la ACJF, se tomó en enero de 1925 la decisión de intensificar su acción en los medios obreros para detener la descristianización y oponerse al comunismo. Al año siguiente, la asociación, que contaba entonces con 6.000 obreros entre sus 100.000 adherentes, se dotó de una comisión obrera central y de un periódico: L'Équipe ouvrièrest.

La experiencia de la guerra también condujo a un cierto número de jóvenes burgueses a tomar conciencia de la situación de las capas más desfavorecidas, y alimentó entre ellos la voluntad de «mezclar filas». De este modo, el deseo de prolongar en la paz la «fraternidad de las trincheras» empujó a un joven estudiante católico de la École Normale Supérieure, Robert Garric, a fundar los Équipes sociales en 1919. Estos equipos reagrupaban a los estudiantes de las «grandes escuelas» (École Normale Supérieure, Ecole Centrale o École Polytechnique) que se dirigían a los barrios populares y barriadas obreras para organizar cursos nocturnos, conferencias y visitas culturales. En 1923 se lanzó el primer equipo femenino. Al año siguiente, 50 equipos sociales actuaban en París y se creó un primer equipo provincial en Épinal ${ }^{52}$. El nacimiento de la Fédération française des éclaireuses da testimonio de este impulso en dirección a los más desfavorecidos. Desde 1912, las UCJF impulsaron diversas experiencias de utilización del método de BadenPowell en el seno de sus Sections cadettes de los barrios populares. Tras la guerra, tres jóvenes protestantes (Violette Mouchon y Antoinette Butte, dos jóvenes burguesas que habían creado una sección de exploradoras en el seno de la Mission populaire évangelique de la calle Marcadet de París, y Georgette Siegrist, de condición más modesta y que introdujo el escultismo en la UCJF de París-Villette)

fueron movilizados como simples soldados.

so Y no, como piensa Philippe Laneyrie (Les Scouts de France..., op. cit., p. 90), porque se comience a confiar al escultismo, del cual aún se desconfía, un medio que parece perdido de antemano. Por el contrario, la penetración en los medios populares significaba en esta época un desafío capital. La delicada y acuciante misión de contrarrestar las influencias revolucionarias y ateas sobre los jóvenes de estos medios se confió entonces a los Scouts de France.

51 Debès, Joseph et Poulat, Émile: L'Appel de la JOC, París, 1986, p. 51.

52 Deffontaines, Pierre: «Le Mouvement des Équipes sociales de Robert Garric (19181939», en Mélanges André Latreille, Lyon, 1972, pp. 225-232; y CHOLVY, Gérard: Histoire des organisations et mouvements..., op. cit., pp. 144-145. 
se dedicaron a organizar a las exploradoras unionistas y a conducirlas progresivamente hacia el camino de la autonomía. En esa misma época, la Maison pour tous de la calle Mouffetard, en el distrito quinto de París, era el escenario de otra iniciativa. Fundada en 1909 por jóvenes miembros del Sillon ${ }^{53}$, este hogar popular fue reorganizado tras la guerra sobre una base no confesional. Entre 1919 y 1920 se constituyeron las primeras unidades de escultismo femenino neutro bajo la iniciativa de Marthe Levasseur, hija del comisario de policía del distrito y que frecuentaba el hogar desde su fundación, y de dos jóvenes burguesas (Margueritte Walter y Renée Sainte-Claire Deville) respectivamente de origen protestante y católico. La Fédération française des éclaireuses —único movimiento que agrupaba en una misma asociación una rama protestante y otra neutra ${ }^{54}$ _ nació en 1921 de la convergencia de estas experiencias llevadas a cabo en diferentes contextos, pero cuyas animadoras tuvieron en común la concepción del escultismo como un medio eficaz para que las jóvenes de las clases populares pudieran gozar de los beneficios de la educación moderna.

Sin embargo, a fines de los años veinte, esta voluntad de «mezclar filas», que no estaba exenta de un cierto paternalismo, se enfrentó al desarrollo de una corriente contraria en el seno del clero y de la juventud católica. Fundada sobre la cooperación de clases y sobre la responsabilidad de las elites respecto de los más pobres, la fórmula de la ACJF y de su Comission ouvrière centrale o incluso de los Équipes sociales de Garric fue denunciada como «demagógica» y «obsoleta» por los que proponían la formación de movimientos especializados, animados por jóvenes del entorno en el que se pretendía actuar. La idea, en realidad, no era nueva. En 1898, durante el Congreso de la ACJF celebrado en Besançon, el principio del «apostolado del semejante por el semejante» fue enunciado abiertamente a propósito de la acción sobre los estudiantes. Se denunciaba que el catolicismo social de viejo estilo no alcanzaba a conquistar un movimiento obrero «sordamente» trabajado por la mística igualitaria del comunismo ${ }^{55}$. Tomando nota de las realizaciones de la Jeunesse ouvrière chrétienne (JOC) belga, fundada en 1925, el abad Guérin lanzó la primera sección de la JOC francesa en Clichy, en los suburbios de París, entre octubre de 1926 y enero de 1927, adelantándose por muy poco a la creación de otra sección en Lille. Una fórmula resume la filosofía del nuevo movimiento: «los apóstoles de los obreros serán los obreros». Sostenido activamente por los jesuitas de Action populaire y por la oficina central de la Union des Euvres catholiques de France, la naciente JOC entabló conversaciones con la ACJF. Ésta admitía la utilidad de

53 Movimiento católico de tendencia social y democrática fundado por Marc Sangnier en 1894, el Sillon fue condenado por el papa Pío X en 1910. Sangnier y sus amigos se sometieron y el movimiento fue disuelto. Sin embargo, muchos antiguo «sillonistas» se encontraron en la fundación de los diferentes movimientos de juventud católicos o neutros en el periodo de entreguerras.

54 Antes de que se añadiese, en 1927, una rama israelita.

55 DeBÈs, Joseph y POUlat, Émile: L'Appel..., op. cit. p. 45; y CHOLvy, Gérard: Histoire des organisations et mouvements..., op. cit., pp. 205-206. 
una organización diferenciada, compuesta únicamente de jóvenes obreros, pero se opuso firmemente a su independencia completa, bajo el modelo de la JOC belga, que en su opinión no hacía caso de la doctrina de la Iglesia sobre la colaboración de clases y privaba a los trabajadores del saber y la experiencia de las elites $^{56}$. Por su lado, los «jocistas» comprendieron que el aval de la AJCF les era indispensable para implantarse en la mayor parte de las diócesis, pero rechazaron la fusión en una asociación general. Formalmente se llegó a un acuerdo en septiembre de 1927 y la JOC se integró en la ACJF a cambio del reconocimiento de su autonomía y de su especificidad. De todos modos, las reticencias respecto de la especialización siguieron siendo fuertes durante todo el periodo. En las diócesis donde los movimientos católicos generales actuaban de forma satisfactoria, o en los casos donde, por el contrario, los efectivos seguían siendo escasos, se entendían mal los llamamientos a la escisión. De igual modo, en las regiones poco industrializadas, donde los antagonismos sociales estaban poco acentuados, la JOC tuvo dificultades de implantación. De todas formas, el movimiento se fue extendiendo. Implantado inicialmente sobre todo en la región de París (68 secciones en 1928) y en el Norte ( 40 secciones en Lille y 25 en Roubaix en 1931), fue ganando progresivamente las cuencas industriales del Este y el Macizo Central. La JOC alcanzó los 20.000 adherentes en 1933 y contaba con 45.000 en 1939. Además de su voluntad de cristianizar al mundo obrero, la JOC quiso despertar el sentido de la responsabilidad y reformar la sociedad sin violencia ${ }^{57}$. Preocupada por no perder el contacto con las aspiraciones del mundo obrero y no dejarse marginar, se implicó en el terreno de las luchas sociales en 1935, precisamente en el momento en que la constitución del Frente Popular polarizaba las esperanzas populares. En marzo de 1936, mientras que la victoria electoral de las fuerzas de izquierda parecía cada vez más probable ${ }^{58}$, la JOC elaboró un plan de reformas donde figuraban especialmente las vacaciones pagadas, los contratos colectivos y la formación profesional. El ejemplo de la JOC condujo, por otra parte, a la formación de otros movimientos especializados. La Jeunesse agricole chrétienne fue fundada en 1929 por jesuitas de la ACJF, seguida de la Jeunesse étudiante chrétienne en 1930, la Jeunesse maritime chrétienne en 1932, y la Jeunesse indépendante chrétienne, que actuaba sobre las clases medias urbanas, en 1936. Sus homólogos femeninos aparecieron muy poco después, pero la JOCF (1928), la JECF (1931), la JACF (1933) y la JICF (1935) se enfrentaron a la sorda competencia de la Ligue patriotique des françaises y de las obras diocesanas.

No obstante, queda claro que la constitución y el desarrollo relativo de los movimientos especializados testimoniaron determinadas evoluciones del catolicismo francés que no fueron ajenas a la experiencia de la Gran Guerra. En efec-

56 Debès, Joseph y Poulat, Émile: L'Appel..., op. cit. pp. 53-54.

57 Cholvy, Gérard e Hilaire, Yves-Marie (dirs.): Histoire religieuse..., tomo 2, op. cit., pp. 391-396; y CHOLVY, Gérard: Histoire des organisations et mouvements..., op. cit., pp. 207-213.

58 Las elecciones legislativas de 26 de abril y 3 de mayo de 1936 fueron ganadas por la coalición frentepopulista que agrupaba a comunistas, socialistas y radicales. 
to, la movilización de los jóvenes sacerdotes y de los seminaristas les permitió compartir las mismas experiencias y las mismas desgracias que sus camaradas de infortunio, y por tanto reducir la distancia que su estatuto como miembros del clero había establecido entre ellos y la población antes de la guerra. Por otro lado, mezclados con la masa de movilizados, estos jóvenes eclesiásticos pudieron tomar conciencia a la vez de la realidad de las condiciones de existencia de sus fieles y, probablemente, de las especificidades culturales de determinados medios sociales. Se comprende entonces que, para algunos de ellos, el funcionamiento clásico de las obras de juventud, fundamentado en la dedicación caritativa de los más ricos y de los más instruidos hacia las capas populares, se juzgara totalmente inadecuado para la empresa de reconquista católica que entonces se planteaba. Por otro lado, la participación activa del catolicismo francés en la Unión Sagrada marcó el fin del conflicto latente que le oponía al campo republicano desde fines del siglo XIX. La condena del movimiento monárquico de l'Action Française por el Papa en 1926 marcó la culminación de un proceso que condujo a la Iglesia católica francesa a aceptar, de mejor o peor grado, la democracia republicana. Se puede, por tanto, interpretar la formación de movimientos de jóvenes obreros o agricultores autónomos como un signo del declive del papel tradicionalmente asignado a los notables en el catolicismo francés, y como revelador de una progresiva penetración de los valores democráticos en su seno.

\section{A MODO DE EPÍLOGO: LAS ASOCIACIONES JUVENILES POLÍTICAS Y LAS FUN- CIONES DE LOS MOVIMIENTOS JUVENILES}

Aunque descrito a grandes trazos, el cuadro de los movimientos de juventud en el periodo de entreguerras no estaría completo si no se abordase la cuestión de los movimientos de carácter político. Aquí también la guerra trajo consigo profundas conmociones. En la derecha y en el centro político, algunas organizaciones habían sido creadas en la primera década del siglo XX, como la Alliance nationale des jeunesses démocratiques o la Association républicaine nationale des jeunes, pero su débil audiencia, vinculada sobre todo a la ausencia de una auténtica estructura partidista de apoyo, las mantenía en una permanente fragilidad. La mayor parte no sobrevivió a la guerra. A la izquierda, la Fédération nationale des jeunesses de France, creada por la SFIO (Section française de la Internationale Ouvrière, el partido socialista francés) en 1912, consiguió reconstituir algunos de sus grupos al final del año 1917. En 1920 contaba con más de 8.000 inscritos mientras que se planteaba la cuestión de su adhesión a la III $^{\mathrm{a}}$ Internacional. Incluso antes del Congreso de Tours, que determinó la separación de la SFIO y del Partido Comunista, y tras duros debates, la mayoría decidió transformar el movimiento en una Fédération nationale des jeunesses communistes de France vinculada a la Internacional Comunista. La «bolchevización» del PC a comienzos de los años veinte y las purgas sucesivas que ello trajo consigo 
transformaron progresivamente a las Jeunesses communistes en una agrupación de escasa entidad alineada dócilmente con las directrices del partido.

Pero la escisión trajo como secuela una profunda herida en el socialismo francés y hasta finales de los años veinte, los grupos supervivientes de las Jeunesses socialistes vegetaron con efectivos muy reducidos, sin estructuras organizativas y prácticamente sin actividad. Las JS reconstituyeron sus fuerzas desde fines de los años veinte, pero se vieron sometidas a un estrecho control por parte de la dirección de la SFIO a través de un comité nacional en el que la mayoría de sus miembros eran nombrados por el partido, que les recluyó en actividades de educación y de tiempo libre y les prohibió todo tipo de participación en debates políticos. Aunque desde 1927 poseyeron un servicio de orden, los Jeunes gardes, que se estructuraron poco a poco y se encargaron de asegurar la protección de los mítines socialistas contra los ataques de los grupos de extrema derecha y de las Jeunesses communistes, la situación sólo cambiaría muy lentamente, con la lucha por la formación del Frente Popular y la victoria electoral de éste en 1936: la JS se transformaría en el movimiento político juvenil más numeroso, con cerca de 55.000 adherentes en 1937, pero las tensiones con la SFIO, principalmente en torno a la política exterior - la postura del gobierno frentepopulista francés ante la guerra civil española o la firma del Pacto de Munich_-, llevaron al partido a disolver algunas de las federaciones juveniles más importantes, como la del Sena o la Federación Nacional de Estudiantes Socialistas, por lo que la JS llegaría a la Segunda Guerra Mundial nuevamente desestructurada ${ }^{59}$.

Los conflictos que agitaron la vida política francesa de los años veinte y de inicio de los años treinta condujeron a un florecimiento de nuevos grupos juveniles. En efecto, las tensiones posteriores a la victoria del Cartel des gauches en las elecciones legislativas de 1924, y la viva emoción que suscitó la demostración de fuerza de los comunistas con motivo del traslado de las cenizas de Jean Jaurès al Panteón el 23 de noviembre de ese año, incitaron a la derecha a dotarse de organizaciones destinadas a asegurar la defensa del orden social y disponer de una «force de frappe» para contrarrestar la agitación revolucionaria. Su complacencia, y, en algunos casos, su apoyo discreto pero activo permitieron a diversas ligas de extrema derecha encuadrar a sus jóvenes militantes más decididos en el seno de grupos de acción que recurrieron deliberadamente a la violencia física. Desde 1924, Pierre Taittinger, un joven diputado de derecha procedente del movimiento bonapartista, lanzo las Jeunesses patriotes (JP). Organizadas en «centurias», con uniforme caqui, boina vasca e insignia, las JP se constituyeron en «tropa de choque» lista para movilizarse tanto para acciones puntuales como para contrarrestar eventuales motines o participar en manifestaciones masivas ${ }^{60}$. Las JP

59 DelPorte, Christian: «Les Jeunesses socialistes...», op. cit., pp. 34-42 y 50 y ss.

60 Chebel D'appollonia, Ariane: L'Extrême droite en France, de Maurras à Le Pen, Bruselas, 1988, pp. 171-181; MILZA, Pierre: «L'Ultra-droite des années trente », en WINOCK, Michel (dir.): Histoire de l'extrême droite en France, París, 1993, pp. 163-164 y TARTAKOWSKY, Danielle: Le Pouvoir est dans la rue. Crises politiques et manifestations en France, París, 1998, pp. 62-63. 
formaron igualmente Phalanges universitaires que llegaron a contar con 4.500 miembros en 1929. Desde 1926, el movimiento de inspiración fascista Le Faisceau disponía de equipos de Legionnaires vestidos con uniforme azul y armados con bastones y fustas, para mantener el orden en las reuniones ${ }^{61}$. La formación de un Faisceau universitaire fue, en esa misma época, la excusa para el desencadenamiento de peleas con los estudiantes monárquicos de l'Action Française. Bajo la denominación de Légions universitaires de la Solidarité française, Volontaires nationaux de la liga de los Croix de Feu, Étudiants francistes o incluso las Chemises vertes de la Ligue de la défense paysanne, las organizaciones juveniles vinculadas a la extrema derecha se multiplicaron entre 1925 y 1935.

La izquierda tampoco se quedó atrás. Del lado comunista, la Association républicaine des anciens combattants (ARAC) se dotó, al igual que la Jeunesse Socialiste, de un servicio de orden para proteger sus manifestaciones. Vestidos con una blusa de tela caqui y una boina vasca con la insignia de la ARAC, y armados con bastón, los Groupes de défense antifascistes se inspiraban abiertamente en los métodos de las Jeunesses patriotes y de los partidos comunistas alemán y belga ${ }^{62}$. No es poco relevante que el jefe del partido radical, Édouard Herriot estigmatizase entonces a aquéllos que, «al estilo de los nazis o de los fascistas, inventan para imitar el gesto del brazo en alto o el del puño cerrado, se arman de insignias y nos conducen hacia la era donde la opinión del ciudadano se reconocerá por el color de su camisa». Por último, con un estilo menos paramilitar, la Ligue d'action universitaire républicaine et socialiste, fundada en 1924, y la Fédération nationale des étudiants socialistes, trataron de «tomar la calle y responder al bastón con el bastón». En el barrio latino libraron verdaderas batallas organizadas contra las JP y los estudiantes de l'Action Française F3. $^{63}$.

Innegablemente, la inclinación de la juventud por el activismo y el radicalismo representaba entonces un valor que las diferentes fuerzas políticas trataban de captar y poner al servicio de sus intereses. En cierta medida, los enfrentamientos que protagonizaron las organizaciones juveniles y las exacciones que cometieron se inscriben en la continuidad de la agitación que había acompañado a las grandes crisis de fines del siglo XIX, como el boulangismo o el affaire Dreyfus, y pueden interpretarse como uno de los accesos de «fiebre» que «calientan» periódicamente la vida política francesa ${ }^{64}$. De todos modos, la gravedad de estos enfrentamientos — cuatro muertos en una colisión entre las Jeunesses patriotes y las Juventudes Comunistas el 25 de abril de 1925, o veinte víctimas mortales en los tumultos antiparlamentarios del 6 de febrero de 1934- y el carácter netamente paramilitar de la mayor parte de las organizaciones juveniles dan testimonio de un incremento de la violencia política que, si bien no alcanzó la misma in-

61 Ibidem; y SIRINELLI, Jean-François: Génération intellectuelle. Khâgneux et normaliens dans l'entre-deux-guerres, París, 1988, pp. 249-250.

62 TARTAKOWSKy, Danielle: Le Pouvoir est dans la rue..., op. cit., p. 63.

63 SIRINELLI, Jean-François: Génération intellectuelle..., op. cit., pp. 251-256.

64 WINOCK, Michel: La Fièure hexagonale. Les grandes crises politiques, 1871-1968, París, 1986. 
tensidad que en Italia, Alemania o España, no fue en Francia menos relevante durante los años veinte y treinta.

De manera más profunda, se podría plantear si la movilización política de la juventud y su propensión a la violencia durante el periodo de entreguerras no fue una muestra, bajo nuevas formas, de la permanencia del papel social asignado tradicionalmente a los jóvenes. Aunque dispusieran de una cierta autonomía de acción, los grupos que hemos mencionado no actuaban nunca en nombre de sus propios intereses, sino siempre al servicio de la defensa del orden social y político o en favor de un proyecto de sociedad alternativo del que no eran autores ni beneficiarios. Sus exacciones no eran el signo de una revuelta antisocial de la juventud, sino que, por el contrario, hacían de ellos los heraldos de una comunidad sociopolítica - de una clase, se podía decir entonces- cuyos intereses eran defendidos por estos grupos. Para decir las cosas de manera aún más lapidaria, se podría plantear si, durante los combates callejeros que les enfrentaron, los jóvenes nacionalistas o los jóvenes revolucionarios no recreaban a su manera las peleas de los mozos de poblaciones rivales típicas de la Francia del Antiguo Régimen.

(Traducción del francés de Eduardo González Calleja) 